\section{CONDIÇÃO GENGIVAL E ÍNDICE DE PLACA BACTERIANA EM ESCOLARES DE REGINOPÓLIS, SÃO PAULO, BRASIL}

\section{GINGIVAL CONDITION AND PLAQUE INDEX IN SCHOOLCHILDREN OF REGINOPÓLIS, SÃO PAULO, BRAZIL}

Cristiane Alves Paz de Carvalho ${ }^{1} /$ Fábio Silva de Carvalho ${ }^{1, *} /$ Thiago Souza Santos ${ }^{1}$

\section{INTRODUÇÃO}

A saúde bucal influencia diretamente a qualidade de vida da criança, e quando acometida por desordens poderá causar impacto negativo que afeta não apenas a criança, assim como toda a família. Em casos mais severos pode levar a destruição completa da unidade dentária assim como o surgimento de dor, acarretando outros problemas, como a perda de apetite e a consequente perda de peso, problemas com a fonação, dificuldade para dormir, baixo desempenho escolar, e interferindo na autoestima da criança (ABANTO et al., 2015; GRANVILLE-GARCIA et al., 2016).

A cárie dentária se caracteriza como o principal problema relacionado à saúde bucal, sendo uma doença de caráter crônico e com grande potencial para causar dor e perda das unidades dentárias quando em processos muito avançados. Sua etiologia é multifatorial e depende da interação das condições ambientais, biológicas e de cunho social para o seu desenvolvimento. Apesar de diversos estudos apontarem que a doença cárie esteja diminuindo no decorrer dos últimos anos, no Brasil fica bem evidente que essa distribuição ainda esteja concentrada na classe mais pobre da população (BOEIRA et al., 2012; NARVAI et al., 2006).

A placa bacteriana ou biofilme dentário se caracteriza como o fator etiológico primário para o acometimento de doenças periodontais. A partir de diversos estudos ficou esclarecido que não se trata apenas de conjunto de bactérias colonizadoras em determinada superfície dental, mas sim como biofilme dentário (HAAS et al., 2012). A formação de biofilme dentário e consequente aparecimento de cárie dentária e doenças periodontias estão diretamente relacionados ao consumo frequente de sacarose e ausência de uma higienização bucal correta (VERNINO, 1998).

\section{RESUMO}

O objetivo do estudo foi avaliar a condição gengival e o índice de placa bacteriana em escolares de Reginópolis-SP Os exames clínicos foram realizados em 356 escolares de ambos os sexos, com idade entre seis e dez anos, por um cirurgião-dentista com auxílio de uma anotadora, previamente padronizados. Para a coleta de dados, foram utilizados o índice proposto por Löe e o índice de Performance de Higiene do Paciente. A maioria dos escolares era do sexo feminino $(52,5 \%)$, tinham entre sete e nove anos de idade $(63,2 \%)$, etnia branca $(70,5 \%)$, moradores da área urbana $(74,4 \%)$ e estudavam no período matutino $(52,0 \%)$. A prevalência de inflamação gengival foi de $78,9 \%$ e o índice de placa bacteriana foi classificado como regular e ruim em $52,2 \%$ dos escolares. Observou-se alta prevalência de inflamação gengival e a maioria dos escolares apresentaram placa bacteriana nas condições regular e ruim, sinalizando a necessidade urgente de ações preventivas e educativas para esse grupo populacional.

Palavras Chave: Saúde Bucal. Condição Gengival. Placa Bacteriana. Escolares.

\section{ABSTRACT}

The objective of the study was to evaluate the gingival condition and plaque index in schoolchildren of ReginópolisSP. The clinical exams were performed in 356 schoolchildren of both sexes, aged between six and ten years, by a dental surgeon with the aid of an annotator, previously standardized. For the data collection, the index proposed by Löe and the Patient Hygiene Performance index were used. The majority of schoolchildren were female (52.5\%), were between seven and nine years old $(63.2 \%)$, white $(70.5 \%)$, urban residents $(74.4 \%)$ and studied in the morning $(52.0 \%)$. The prevalence of gingival inflammation was $78.9 \%$ and the plaque index was classified as regular and poor in $52.2 \%$ of schoolchildren. It was observed a high prevalence of gingival inflammation and most of the students presented plaque in regular and bad conditions, signaling the urgent need for preventive and educational actions for this population group.

Keywords: Oral Health. Gingival Condition. Dental Plaque. Schoolchildren.

Submetido em: 05 de abr. 2019

Aceito em: 17 de dez. 2019

${ }^{1}$ Universidade Estadual do Sudoeste da Bahia, Jequié, Bahia - Brasil

*E-mail para correspondência: fscarvalho@uesb.edu.br

Rev. ComCiência - dez. 2019, vol. 4, no. 5, p. 35-40 / doi: 10.36112/issn2595-1890.v5i2.p35-40 
Como medida preventiva contra a formação do biofilme dentário encontra-se um dos métodos mais simples e eficazes, que é a escovação e higienização correta da cavidade bucal para que ocorra uma desorganização deste biofilme (VERNINO, 1998).

Estudos relatam que as ações educativas em saúde bucal, possui um efeito pequeno e passageiro quanto à formação e acúmulo de biofilme dentário, no entanto, apresenta-se de forma positiva no que diz respeito a proporcionar conhecimento ao indivíduo das medidas que devem ser adotadas para evitar os problemas em saúde bucal (KAY; LOCKER, 1996). Devido à escovação ser um método simples e de fácil acesso a população, a implementação de medidas educativas é de fundamental importância, pois é na infância que o indivíduo está mais propenso a aprender e assim levar para sua vida adulta, resultando em um programa de saúde bucal de qualidade para a população (FERREIRA et al., 2011).

O objetivo desse estudo foi avaliar a condição gengival e o índice de placa bacteriana em escolares de Reginópolis-SP.

\section{METODOLOGIA}

$\mathrm{O}$ estudo foi realizado no município de Reginópolis - SP que está localizado na região centro-oeste do Estado de São Paulo e situado a 411 $\mathrm{km}$ da capital, cuja população era de 7323 pessoas em 2010 (IBGE, 2011).

Trata-se de um estudo epidemiológico censitário, transversal, descritivo e de natureza quantitativa, realizado no ano de 2011 com escolares entre seis e dez anos de idade da única escola de ensino fundamental I de Reginópolis - SP, localizada em área urbana. A população de escolares entre seis e dez anos de idade do município era de 386 e fizeram parte do estudo 356 crianças.

Para verificar as condições gengivais dos escolares foi adotado o índice proposto por Löe (1967) que avalia a presença ou ausência de sinais inflamatórios e sangramento após sondagem, sendo que a presença de sangramento poderá ser provocada ou espontânea. A sonda percorre o sulco gengival, da direção das faces proximais, tanto por vestibular quanto por lingual, e após observa-se presença ou ausência de sangramento no sulco gengival e o registro é feito por dente. (LÖE, 1967).

Para avaliar a presença de placa bacteriana foi utilizado o Índice de Performance de Higiene do Paciente (PHP). Esse índice é específico para placa bacteriana e avalia a existência de placa nas superfícies vestibulares do primeiro molar superior direito e esquerdo e incisivo central superior direito, na superfície lingual do primeiro molar inferior esquerdo, na superfície vestibular do incisivo central inferior esquerdo e na superfície lingual do primeiro molar inferior direito. Para o cálculo do índice, a superfície dentária de cada dente analisado é dividida em cinco áreas, sendo atribuído escore de zero a cinco, e cada área recebe o escore zero se não existir placa e escore um se houver; no final serão somados os escores de todos os dentes, dividindo pelo número de faces analisadas para obter o índice individual, o qual será classificado em muito bom, bom, regular e ruim (PODSHADLEY; HALEY, 1968).

Todos os exames clínicos foram realizados por um cirurgião-dentista com auxílio de uma anotadora, previamente treinados e padronizados por um examinador "padrão ouro", visando garantir a uniformidade de interpretação, compreensão e aplicação dos critérios adotados. Os exames foram realizados no ambiente escolar, com iluminação natural, utilizando-se sondas OMS e espelhos bucais planos. Para avaliar a concordância intraexaminador foi realizado o reexame de $10 \%$ da população durante a fase de coleta dos dados (Kappa $=0,88$ ).

Os dados foram processados em planilha do programa Office Excel 2016® e os resultados foram apresentados de acordo com análise descritiva. Para análise dos dados a população foi categorizada por sexo (masculino e feminino), idade (6 a 10 anos), etnia (branco e outras etnias), local de moradia (urbana e rural) e período de estudo (matutino e vespertino).

Para o desenvolvimento deste estudo, os pesquisadores seguiram fielmente a Resolução 196/96 do Conselho Nacional de Saúde, sendo resguardados todos os princípios éticos que norteiam o desenvolvimento de pesquisa com seres humanos. Esse estudo só foi realizado após ser submetido e aprovado pelo Comitê de Ética e Pesquisa (CAAE: 0053.0.224.000-11) e os dados da pesquisa foram coletados após autorização dos responsáveis pelos participantes da pesquisa através de assinatura do Termo de Consentimento Livre e Esclarecido.

\section{RESULTADOS}

Participaram desse estudo censitário 356 escolares entre seis e dez anos de idade da única escola municipal de ensino fundamental 1 de Reginópolis - SP, no ano de 2011. Na tabela 1 pode-se visualizar a distribuição dos escolares de acordo com sexo, idade, etnia, local de moradia e período de estudo. 
Tabela 1 - Distribuição dos escolares de acordo com sexo, idade, etnia, local de moradia e período de estudo. Reginópolis-SP, 2011

\begin{tabular}{|c|c|c|}
\hline & $\mathbf{n}$ & $\%$ \\
\hline \multicolumn{3}{|l|}{ Sexo } \\
\hline Masculino & 169 & 47,5 \\
\hline Feminino & 187 & 52,5 \\
\hline \multicolumn{3}{|l|}{ Idade } \\
\hline 6 anos & 68 & 19,1 \\
\hline 7 anos & 77 & 21,6 \\
\hline 8 anos & 78 & 21,9 \\
\hline 9 anos & 70 & 19,7 \\
\hline 10 anos & 63 & 17,7 \\
\hline \multicolumn{3}{|l|}{ Etnia } \\
\hline Branco & 251 & 70,5 \\
\hline Outras etnias & 105 & 29,5 \\
\hline \multicolumn{3}{|c|}{ Local de moradia } \\
\hline Área urbana & 265 & 74,4 \\
\hline Área rural & 91 & 25,6 \\
\hline \multicolumn{3}{|c|}{ Período de estu- } \\
\hline \multicolumn{3}{|l|}{ do } \\
\hline Matutino & 185 & 52,0 \\
\hline Vespertino & 171 & 48,0 \\
\hline Total & 356 & 100,0 \\
\hline
\end{tabular}

No que diz respeito às condições gengivais dos escolares, as crianças com seis anos de idade apresentaram condição gengival mais saudável (36,8\%), enquanto as crianças com oito anos de idade apresentaram algum grau de inflamação (85\%). A prevalência de inflamação gengival nos escolares, foi de $78,9 \%$ dos casos examinados (Tabela 2).
Tabela 2 - Condições gengivais dos escolares de acordo com sexo, idade, etnia, local de moradia e período de estudo. Reginópolis-SP, 2011

\begin{tabular}{ccc} 
Saudável & $\begin{array}{c}\text { Inflamação } \\
\text { Leve }\end{array}$ & $\begin{array}{c}\text { Inflamação } \\
\text { Moderada }\end{array}$ \\
\hline$\%$ & $\%$ & $\%$
\end{tabular}

Sexo

\begin{tabular}{|c|c|c|c|}
\hline Masculino & 18,1 & 43,6 & 38,3 \\
\hline Feminino & 23,8 & 38,3 & 37,9 \\
\hline \multicolumn{4}{|l|}{ Idade } \\
\hline 6 anos & 36,8 & 36,3 & 27,0 \\
\hline 7 anos & 20,1 & 50,4 & 29,4 \\
\hline 8 anos & 15,0 & 44,2 & 40,8 \\
\hline 9 anos & 19,0 & 35,2 & 45,7 \\
\hline 10 anos & 15,3 & 36,0 & 48,7 \\
\hline \multicolumn{4}{|l|}{ Etnia } \\
\hline Branco & 21,2 & 40,3 & 38,4 \\
\hline $\begin{array}{l}\text { Outras } \\
\text { etnias }\end{array}$ & 20,8 & 42,1 & 37,1 \\
\hline \multicolumn{4}{|l|}{ Local de } \\
\hline \multicolumn{4}{|l|}{ moradia } \\
\hline $\begin{array}{l}\text { Área } \\
\text { urbana }\end{array}$ & 23,0 & 41,6 & 35,5 \\
\hline Área rural & 15,8 & 38,6 & 45,6 \\
\hline \multicolumn{4}{|l|}{ Período } \\
\hline \\
\hline \multicolumn{4}{|l|}{ estudo } \\
\hline Matutino & 22,4 & 43,8 & 33,8 \\
\hline Vespertino & 19,7 & 37,6 & 42,7 \\
\hline Total & 21,1 & 40,8 & 38,1 \\
\hline
\end{tabular}

As crianças de seis anos de idade, de etnia não branca, que residem na zona rural do município e estudam no turno vespertino foram avaliadas em boas condições em relação ao índice de placa bacteriana. (Tabela 3 )
Tabela 3 - Índice de placa bacteriana dos escolares de acordo com sexo, idade, etnia, local de moradia e período de estudo. Reginópolis-SP, 2011

\begin{tabular}{|c|c|c|c|}
\hline & $\begin{array}{c}\text { Bom } \\
\%\end{array}$ & $\begin{array}{c}\text { Regular } \\
\%\end{array}$ & $\begin{array}{c}\text { Ruim } \\
\%\end{array}$ \\
\hline \multicolumn{4}{|l|}{ Sexo } \\
\hline Masculino & 47,3 & 5,9 & 46,7 \\
\hline Feminino & 48,1 & 5,3 & 46,5 \\
\hline \multicolumn{4}{|l|}{ Idade } \\
\hline 6 anos & 87,3 & 4,8 & 7,9 \\
\hline 7 anos & 71,4 & 4,3 & 24,3 \\
\hline 8 anos & 44,9 & 9,0 & 46,1 \\
\hline 9 anos & 22,1 & 2,6 & 75,3 \\
\hline 10 anos & 19,1 & 7,4 & 73,5 \\
\hline \multicolumn{4}{|l|}{ Etnia } \\
\hline Branco & 41,8 & 6,4 & 51,8 \\
\hline $\begin{array}{l}\text { Outras } \\
\text { etnias }\end{array}$ & 61,9 & 3,8 & 34,3 \\
\hline \multicolumn{4}{|l|}{$\begin{array}{l}\text { Local de } \\
\text { moradia }\end{array}$} \\
\hline $\begin{array}{l}\text { Área urba- } \\
\text { na }\end{array}$ & 42,3 & 6,4 & 51,3 \\
\hline Área rural & 63,7 & 3,3 & 33,0 \\
\hline \multicolumn{4}{|l|}{$\begin{array}{l}\text { Período de } \\
\text { estudo }\end{array}$} \\
\hline Matutino & 29,2 & 9,2 & 61,6 \\
\hline Vespertino & 67,8 & 1,8 & 30,4 \\
\hline Total & 47,8 & 5,6 & 46,6 \\
\hline
\end{tabular}

\section{DISCUSSÃO}

Por se tratar de um estudo censitário, a maior limitação para seu desenvolvimento foi obter as autorizações dos responsáveis para participação no estudo o que levou os pesquisadores a retornarem mais vezes ao ambiente escolar para a realização da coleta de dados. No entanto, vale salientar que foram avaliadas 356 crianças entre seis e dez anos de idade, corres- 
pondendo a 92,2\% da população de escolares do município dessa faixa etária.

A cárie dentária continua sendo considerada um problema de saúde pública, medidas de prevenção e tratamento precisam ser implementadas para o controle da doença. $\mathrm{O}$ acúmulo da placa bacteriana dentária tem forte relação com o desenvolvimento da cárie dentária e também das doenças gengivais e periodontais, sendo necessária à sua desorganização para a prevenção e controle dessas doenças. (COSTA et al., 2014)

$\mathrm{O}$ atual estudo avaliou a condição gengival e o índice de placa bacteriana em um grupo de escolares entre seis e dez anos de idade no município de Reginópolis - SP. Observou-se alta prevalência de inflamação gengival entre os escolares $(78,9 \%)$, assim como foi relatado em outros estudos. (RODRIGUES et al., 2016; CHAVES et al., 2011)

Em Reginópolis - SP, verificouse maior prevalência de inflamação gengival em escolares do sexo masculino, corroborando com os estudos realizados em Oliveira do Bairro Aveiro (Portugal) e São Bernardo do Campo - SP. (RODRIGUES et al., 2016; CHAMBRONE et al., 2010)

Em relação à idade, no presente estudo as crianças mais velhas, no caso entre oito e dez anos, foram as que apresentaram maior prevalência de inflamação gengival, enquanto o contrário foi observado em outros estudos, em que crianças mais novas estão mais propensas a desenvolverem tal condição (CHAMBRONE et al., 2010; BARRETO et al., 2013).

A maioria das crianças examinadas era de etnia branca $(70,5 \%)$, no entanto, quanto à avaliação de inflamação gengival os escolares de outras etnias apresentaram prevalência um pouco maior, porém ambos apresentaram altos índices de inflamação gengival, assim como verificados em outros estudos. (BORRELL et al.,2005; SUSIN, 2004)

Quanto ao local de moradia dos escolares, a maioria residia na área urbana do município $(74,4 \%)$, e as crianças que moravam na área rural apresentaram maior prevalência de inflamação gengival, principalmente na condição moderada. (FONSECA et al., 2015) Assim como foi observado entre as crianças que estudavam no período vespertino.

Em relação ao índice de placa bacteriana observou-se que a maioria dos escolares apresentou condições regular e ruim $(52,2 \%)$, corroborando com os resultados encontrados na literatura científica (JUNIOR et al., 1988; FELDENS et al., 2016).

No presente estudo, o sexo masculino apresentou maior prevalência de placa bacteriana, similar ao encontrado em outras pesquisas (FONTES et al., 2014; CHAMBRONE et al.,2010).

Quando comparada a relação da idade com o índice de placa bacteriana no presente estudo as crianças entre 9 e 10 anos, no caso as mais velhas da pesquisa, foram as que apresentaram maiores índices de placa, sendo que a condição ruim, foi a mais prevalente neste estudo, diferente do que foi observado em outros estudos, em que crianças mais jovens tendem a possuir esse índice mais elevado (FONTES et al., 2014; CHAMBRONE et al.,2010).

Quanto à etnia, o índice de placa principalmente na condição ruim foi mais prevalente em crianças brancas (58,2\%). Em estudo comparativo, não ficou determinada a relação da placa bacteriana com a raça/etnia, visto que essa variável geralmente está atrelada as condições socioeconômicas. (BORRELL; PAPAPANOU, 2005)

Em relação ao local de moradia, crianças que moravam na área urbana do município $(57,7 \%)$ apresentaram maior prevalência de placa bacteriana, principalmente na condição ruim. Quando comparado a outro estudo, não se identificou como um fator de prevalência correlacionado ao índice de placa. FONSECA et al., 2015)

Ao correlacionar o índice de placa com o período de estudo dos escolares, foi observado que crianças que estudavam no período matutino apresentavam alta prevalência de placa bacteriana $(69,8 \%)$ principalmente na condição ruim.

A realização deste estudo, de cunho epidemiológico e censitário é de fundamental importância tanto para a ciência quanto para o município de Reginópolis - SP, onde foi realizado, pois através dele tem a possibilidade dos governantes juntamente com a secretaria de saúde do município de interferir de forma incisiva nos fatores que ocasionam esses agravos nos escolares, assim criando medidas mais assertivas para prevenir esses problemas em saúde bucal. A implementação de ações educativas e preventivas é de fundamental importância para buscar reverter esse quadro, levando conhecimento tanto para os escolares, como professores e familiares, sendo de forma integrada para melhor se aplicar esta medida. O papel dos educadores se torna fundamental nesse processo, uma vez que no ambiente escolar suas ações vão além de consolidar as práticas de cuidado em saúde bucal desenvolvidas no âmbito familiar, mas também de propiciar aos escolares mais conhecimento na adoção de hábitos saudáveis promovendo melhoria na qualidade de vida desses indivíduos. (BARRETO et al., 2013) A 
partir deste estudo que foi realizado em 2011, nota-se a importância da realização de novos estudos para investigar tais condições no decorrer do tempo, identificando o que mudou no quadro apresentado, ou quais medidas precisam ser adotadas ou modificadas para garantir uma saúde bucal de qualidade tanto para os escolares como para a população como um todo.

\section{CONCLUSÃO}

Observou-se alta prevalência de inflamação gengival nos escolares examinados e a maioria apresentou placa bacteriana nas condições regular e ruim. Há necessidade urgente de implementar estratégias preventivas e educativas, que são recursos eficazes e simples, que poderão interceptar e controlar esses problemas de saúde bucal apresentados por este grupo populacional.

\section{REFERÊNCIAS}

ABANTO, J. et al. Concordância entre os relatos do núcleo familiar em relação à qualidade de vida da criança. Rev. Assoc. Paul. Dent.; v.68, n.1, p.44-8, jan-mar, 2015. Disponível em:

<http://revodonto.bvsalud.org/pdf/apcd/ v68n1/a06v68n1.pdf>

\section{BARRETO DB et al. Avaliação da} eficácia de uma atividade educativopreventiva com pré-escolares: estudo piloto de um ensaio clínico randomizado. Arq. Odontologia, Belo Horizonte, v. 49, n. 3, p. 113 -121, jul/set, 2013. Disponível em:

$<$ http://revodonto.bvsalud.org/scielo.php ?script=sci_arttext\&pid=S151609392013000300002\&lng=pt\&nrm=iso $>$
BOEIRA, G.F. et al. Caries is the main cause for dental pain in childhood: findings from a birth cohort. Caries Res. v.46 n.5, p.488-95, 2012. Disponível em: <

https://www.ncbi.nlm.nih.gov/pubmed/2 2813889>

\section{BORRELL RN, PAPAPANOU PN.}

Analytical epidemiology of periodontitis. J Clin Periodontol, New York, v. 32, 2005. Suppl 6 : 132-58, 2005. Disponível em: < https://onlinelibrary.wiley.com/doi/full/1 0.1111/j.1600-051X.2005.00799.x>

CHAMBRONE, L. et al. Prevalência e severidade de gengivite em escolares de 7 a 14 anos: condições locais associadas ao sangramento à sondagem. Ciência $\boldsymbol{\&}$ Saúde Coletiva, São Paulo, v. 15, n. 2, p. 337-343, 2010. Disponível em:

<http://www.scielo.br/scielo.php?script= sci_arttext\&pid=S1413-

$81232010000200008 \& \operatorname{lng}=\mathrm{en} \& n r m=$ iso $>$.

CHAVES, R.A. et al. Consultório odontológico na escola: análise da saúde gengival e do nível de higiene oral. RGO - Rev. Gaúcha Odontol., Porto Alegre, v.59, n.1, p.29-34, jan./mar., 2011. Disponível em: <

http://www.revistargo.com.br/viewartic e.php?id=1749\&layout=abstract $>$

COSTA, A.M.D.D. et al. Avaliação do índice de biofilme dentário do deterioro e dos cuidados relativos ao armazenamento e desinfecção das escovas dentais de crianças de uma creche do sul de Minas Gerais. Braz J Periodontol, Minas Gerais, v. 24, n. 2, p. 07-12, 2014. Disponível em: $<$ http://www.scielo.br/scielo.php?script= sci_arttext\&pid=S1806$83242016000100230 \& \operatorname{lng}=$ en $\& n r m=$ iso $>$.
FELDENS, E.G. et al. Distribution of plaque and gingivitis and associated factors in 3- to 5-year-old Brazilian children. J Dent Child. v. 73, n.1, p. 410, 2006. Disponível em: <

https://www.ncbi.nlm.nih.gov/pubmed/1 6734306>

FERREIRA, E.B.; ABREU, T.Q.; OLIVEIRA A.E.F. Modelos assistenciais em saúde bucal no Brasil: revisão de literatura. Rev. Pesq. Saúde. v.12, n. 3, p. 37- 42, 2011. Disponível em: < http://www.periodicoseletronicos.ufma.b r/index.php/revistahuufma/article/view/1 138>

FONSECA, E.P. et al. Relação entre condição gengival e fatores sociodemográficos de adolescentes residentes de uma região brasileira. Ciência \& Saúde Coletiva, Minas Gerais, v.20, n.11, p. 3375-3384, 2015. Disponível em: < http://www.scielo.br/scielo.php?pid=S1 413-

$81232015001103375 \&$ script $=$ sci_abstra ct\&tlng $=\mathrm{pt}>$

FONTES. M.L. et al. Avaliação da condição gengival de escolares. Odonto, São Paulo, v. 22, n. 43-44, p.13-20,

2014. Disponível em: <

https://www.metodista.br/revistas/revist as-

ims/index.php/Odonto/article/view/4500 $>$

GRANVILLE-GARCIA, A.F. Et al.

Parental influence on children's answers to an oral-health-related quality of life questionnaire. Braz Oral Res.14 ed. v.30, n.1: e14, Mar. 2016. Disponível em: <

http://www.scielo.br/scielo.php?script=s ci_arttext\&pid=S1806-

83242016000100230> 
HAAS, A.N. et al. Daily biofilm control and oral health: an epidemiological challenge consensus-brazilian advisory panel in oral health. Braz J Periodontol. v. 22, n.3, p. 40-46, 2012. Instituto Brasileiro de Geografia e Estatística (IBGE). Disponível em: <http://www.ibge.gov.br>.

JUNIOR, E.M. et al. Correlação entre os critérios clínicos do índice de placa e a condição histológica dos tecidos gengivais. Rev Odontol UNESP. v. 17, n.1/2, p. 123-138, 1988. Disponível em: < http://www.revodontolunesp.com.br/arti cle/588017457f8c9d0a098b4647>

KAY, E.J.; LOCKER D. Is dental health education effective: a systematic review of current evidence. Community Dent Oral Epidemiol. v. 24, p. 231- 5, 1996. Disponível em: < https://www.ncbi.nlm.nih.gov/pubmed/8 871028>

LÖE $\mathrm{H}$. The gingival index, the plaque index and the retention index systems. $\mathbf{J}$ Periodontol, v. 38, p. 610, 1967. Disponível em: <

https://www.ncbi.nlm.nih.gov/pubmed/5 237684>

Narvai, P.C. et al. Cárie dentária no Brasil: declínio, polarização, iniquidade e exclusão social. Rev. Panam Salud Publica. v.19, n.6, p.385-9, 2006.

Disponível em: < https://scielosp.org/pdf/rpsp/2006.v19n6 /385-393/pt>

PODSSHDLEY, A.G.; HADLEY, J.V. A method for evaluating oral higyene performance. Public Health Rep. v. 83, p. 259-64, 1968. Disponível em: < https://www.ncbi.nlm.nih.gov/pmc/articl es/PMC1891029/>
RODRIGUES, A.P.; MATIAS F.; FERREIRA, M.M. Escovagem de dentes em ambiente escolar e redução do índice de placa bacteriana: avaliação da efetividade de um projeto de saúde oral.

Rev. Port. Saúde Pública. v. 34, n. 3, p. 244-249, 2016. Disponível em: < https://www.sciencedirect.com/science/a rticle/pii/S0870902516300128>

\section{SUSIN C. Doenças periodontais em} uma população urbana representativa no sul do Brasil. 2004. (Tese de Doutorado). Noruega: Faculdade de Odontologia da Universidade de Bergen.

VERNINO, A.R. Etiologia das Doenças Periodontais. In: JUNIOR, P.F.; VERNINO, A.R. Fundamentos da Periodontia. 3a ed. São Paulo: Premier, c1998. p. 13-19. 